\title{
The Effect of Six Thinking Hats and Critical Thinking on Speaking Achievement
}

\author{
Ummu Hani, Ismail Petrus, Margaretha Dinar Sitinjak \\ Sriwijaya University, Palembang, Indonesia \\ ummuhanialkaff@gmail.com
}

\begin{abstract}
The Six Thinking Hats (STH) is an interesting strategy, which requires students to think and discuss an issue from different points of view. The objectives of this study were to find out the students' speaking achievement after being taught by the STH, the interaction effect of STH and critical thinking on students' speaking achievement and speaking achievement among the students who had high, mid and low levels of critical thinking. Factorial design was used in this study, which involved experimental and control groups. The sample of this study covered 48 students that were equally divided into experimental and control group. The result showed that the experimental group had better improvement in speaking achievement than the control group. However, there was a partial significant interaction effect of the STH and students' critical thinking on speaking achievement, which was on pronunciation aspect. Besides, the results also showed there were significant differences among the levels of students' critical thinking in the experimental group especially in comprehension, pronunciation, and fluency aspects.
\end{abstract}

Keywords: Six Thinking Hats, speaking achievement, critical thinking

\section{INTRODUCTION}

In foreign language teaching and learning, the ability to speak is an essential skill since it is the basic for communication. Ironically, the fact shows that Indonesian students are still in the low level of the speaking competence (Akhyak \& Indramawan, 2013). Based on the observation and an interview that was done by the writer to some senior high school students, the problems of EFL learners were lack of motivation to speak. Moreover, the students seldom practice their spoken English in the class. It was also supported by Febriyanti (2011) who stated that students did not acquire the target language and they were not used to taking part in classroom discussion.

Besides, when speaking, students need to use their knowledge so that they know what they are going to say and express. Therefore, students should not only have the ability to get information passively but also practice to use their critical thinking to select some information that are most appropriate for their purpose. Accordingly, critical thinking plays an important role to students especially when they speak. Sanavi and Tarighat (2014) revealed that raising critical thinking awareness explicitly had a significantly positive impact on the speaking proficiency on their study. Unfortunately, Asian students are widely regarded as lacking critical attitude and being ignorant of the principles of analysis and critique (Egege and Kutieleh, 2004). Besides, the students in Indonesia tend to accept opinion especially on the current news of politics, corruption, and education, without evaluating them appropriately. This is probably because most of them previously studied at primary and secondary schools, which typically applied teacher-centered approach. Therefore, expressing ideas in English both communicatively and critically is not always easy for students (Masduqi, 2011). Thus, it is important to create a comfortable situation in the classroom where students are not afraid to speak and enjoy sharing their ideas and thoughts; one of the strategies is using Six Thinking Hats (STH)

STH is introduced by Edward de Bono in 1986, which requires students to expand their way of thinking about a topic by wearing six different thinking hats. According to Bono (2004), "the Six Thinking Hats, however, encourages parallel thinking, where everyone explores all sides of an issue at the same time." In conducting the study, the students who consist of 6 members in a group were given the hats which had different functions in solving an issue: (a) White hat: thinks about the data, facts, information known or needed from the topic/problem; (b) Black hat: focuses on difficulties, potential problems and why something may not work; (c) Red hat: discusses about feelings, hunches, instinct, and intuition; (d) Green hat: discusses more about creativity, possibilities, alternatives, solutions, new ideas; (e) Yellow hat: focuses on values and benefits of why something may work; (f) Blue hat: discusses about process, focus, next steps, action plans and decision making about the topic/problem given. Thus, the writer was intended to see whether the STH Strategy and Critical Thinking gave positive effects on the Speaking Achievement of the Tenth Grade Students of SMA N 1 Palembang.

\section{METHODS}

In this study, Factorial design was used. It involved two groups: one experimental group and one control group. The experimental group received treatment, while the control group did not. In conducting the research, the writer used pretest posttest factorial design. The process of teaching and learning in the experimental group was conducted for 24 meetings and it was held out of the regular class hours.

The population of this study was the tenth grade students of SMA Negeri 1 Palembang located in Jalan Srijaya Negara, Bukit Besar, Palembang. There were 14 classes (9 Natural Science and 5 Social Science) of tenth grade students 
in this school, which each class consisted of 37 to 40 students in one class.

To take the sample from the population, the students were selected from three levels of critical thinking (high, mid, and low). In this case, 4 classes had the same teacher to be taken as the sample. Those classes were given the critical thinking test to see whether the students have the high, mid and low levels of critical thinking. The writer took 16 students for each level of critical thinking. Then they were divided into two groups (experimental and control groups). Thus, there were 24 students in the experimental group, and 24 students in the control group.

\subsection{Data Collection and Data Analysis 2.3.1 Speaking Test}

The speaking test was conducted twice (pre-test and post-test) for both experimental and control groups. The writer used the monolog-speaking test by giving them some guideline questions in the form of argumentative texts. The students were given 3 to 5 minutes to talk using their own words based on the topic chosen from the lottery. To score students' speaking achievement, analytical speaking rubric of SOLOM was used. There are five aspects in this rubric, namely comprehension, fluency, vocabulary, pronunciation, and grammar.

\subsubsection{Critical Thinking Test}

In measuring students' critical thinking, the writer used Cornell Critical Thinking Test Level X (CCTT-X). In order to check and make sure whether the test was valid to be given to the sample, the writer tried out the test to the non-sample students.

\subsubsection{Validity and Reliability of the tests}

In relation to the validity of speaking test, the content validity was used in this test. The writer used 8 topics for the speaking test, which were in accordance with the expert judgments. Besides, to see whether the critical thinking test was valid, the writer tried out the test to the students who had the same level before it is administered to the sample. The result of the try out showed that from 72 questions of critical thinking test there were 25 invalid items which got below $r_{\text {table }} 0.444$ and the valid items were 47 .

To judge the speaking test was reliable or not, the writer applied inter-rater reliability. Inter rater reliability for the speaking test was used by following the procedure: (1) two raters' score the test based on the recordings and rubric, (2) the calculation of raters' score using Pearson Product Moment correlation. The result showed that the coefficient were 0.938 , $0.818,0.740$, and 0.849 . Since the coefficient were higher than 0.70 , the speaking test was considered reliable.

\section{RESULTS}

\subsection{Results of Speaking Test in Both Groups}

Both experimental and control groups were given the pretest and posttest to know their speaking achievement. The result showed that there were some significant difference between those who were taught by Six Thinking Hats and those who were not. The following was the score distribution of speaking achievement in both groups.

Table 1. Results of Speaking Achievement of Both Groups

\begin{tabular}{|c|c|c|c|c|c|c|c|c|c|c|c|c|c|}
\hline \multirow{3}{*}{$\begin{array}{l}\text { Soonc } \\
\text { Interval }\end{array}$} & \multirow{3}{*}{$\begin{array}{l}\text { Level } \\
\text { Gatezery }\end{array}$} & \multicolumn{6}{|c|}{ ContiolGno-p } & \multicolumn{6}{|c|}{ Esperimentsi Group } \\
\hline & & ו & $=1$ & & fless & $. t=1$ & & Prelt & & & & Mes. & \\
\hline & & & $k$ & PAlsur & 1 & $x$ & Assr & 1 & $\%$ & M:su & 1 & 3 & B:ws \\
\hline 21.25 & [xullent & & & & J & 52 & & & & & 5 & 20.8 & \\
\hline 15.70 & fires & 1 & 17) & & $=$ & $1 \%$ & & 1 & 4) & & 1. & int & \\
\hline 11.15 & A.telat: & 16 & 6. & 22.33 & 36 & jis & 12.52 & $1 /$ & iv.3 & 2.32 & $i$ & $2 y_{.2}$ & 28.31 \\
\hline $6 \cdot 10$ & lever & $=$ & a. 8 & & 1 & 13 & & 5 & 20.3 & & - & - & \\
\hline 15 & Very Ponr & 3 & 8.2 & & & & & 1 & 4.9 & & & & \\
\hline
\end{tabular}

\subsection{Results of Critical Thinking Test}

To find out the students' critical thinking level, the writer gave all students which consisted of 4 classes $(\mathrm{N}=151)$ the critical thinking test and classified the scores based on the score intervals and the level categories (low, medium and high).

The results showed that the mean score of critical thinking of all students was 27.75 and the standard deviation was 5.45. From 151 students, 18 students $(11.9 \%)$ were in the low level of critical thinking, 107 students $(70.9 \%)$ were in medium level of critical thinking and 26 students $(17.2 \%)$ were in high level of critical thinking.

\subsection{Statistical Analyses}

\subsubsection{Paired Samples t-test and Independent t-test}

The writer analyzed the result of speaking achievement before and after the intervention using paired sample t-test and compared the results of the posttest in both groups using independent sample t-test. Table 2 presents the summary of the comparison between both groups.

Table 2. Summary of Paired and Independent Sample t-test of

\begin{tabular}{|c|c|c|c|c|c|c|c|c|}
\hline & & & i & Ac & & & & \\
\hline \multirow[t]{2}{*}{$\begin{array}{l}\text { Splueskint } \\
\text { Aspe:ts }\end{array}$} & \multicolumn{2}{|c|}{$\begin{array}{l}\text { Mrant if } \\
\text { Contol Grove }\end{array}$} & \multicolumn{2}{|c|}{$\begin{array}{l}\text { Atean af } \\
\text { Experim:a:s! } \\
\text { Group }\end{array}$} & \multirow{2}{*}{ 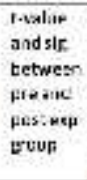 } & \multirow{2}{*}{ 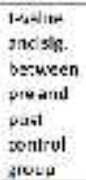 } & \multirow{2}{*}{ 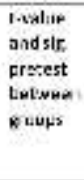 } & \multirow{2}{*}{ 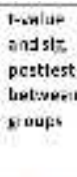 } \\
\hline & F: & Ps. & $9:$ & Fost & & & & \\
\hline \multirow[t]{2}{*}{ Spraking Tn:-A } & $17 \mathrm{Br}$ & $175 ? 3$ & 12317 & 18313 & $|7.1\rangle \mid$ & $m$ & $0.7 n$ & $7 \sin 5$ \\
\hline & & & & & & 20 & & \\
\hline \multirow[t]{2}{*}{ Compruliansian } & Bt: & $7: 1 \% 3$ & 7,53 & 1.317 & $1 . N$. & SNM & AMF:4 & Wext \\
\hline & & & & & $0 . x$ & $\therefore 8 t$ & 0.22 & 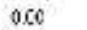 \\
\hline \multirow[t]{2}{*}{ Husro: } & $2.2 \pi$ & 2,11 & 2.jo & J.A. & (x): & 1.90 & V.J.4 & \\
\hline & & & & & $n r$ & ans & 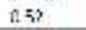 & ars \\
\hline \multirow[t]{2}{*}{ Vucabulizy } & $32 \pi$ & R.4:3 & $3 \%$ & $3: 56$ & $8.2: 7$ & 7.'ity & $1,3 \%$ & 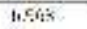 \\
\hline & & & & & ve & $\therefore$ & v.s. & \\
\hline \multirow[t]{2}{*}{ Prenurchition: } & $23 x$ & 7313 & 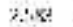 & $3 \times 13$ & x.2. & 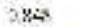 & $1.0 ; 4$ & $x-4$ tit \\
\hline & & & & & $n r$ & $71 \mathrm{a}$ & $n m$ & art \\
\hline Groment & 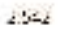 & 2xis & $2.2+16$ & J.4. & $\begin{array}{l}\text { t. } 3=2 \\
117\end{array}$ & $2.2 \%$ & $\begin{array}{l}1.1 \% \\
1 . \% 1\end{array}$ & $\begin{array}{l}=\leq E \\
\text { uica! }\end{array}$ \\
\hline
\end{tabular}

Based on the calculation in paired samples statistical table of the experimental and control groups in the pretest and posttest, the writer found that the students in the control group did not make any significance difference in their speaking achievement while the students in the experimental group had some significance difference before and after being taught by the Six Thinking Hats. In addition, based on the results of independent samples t-test, the value of t-obtained in the posttest between both experimental and control groups was 
7.405 with the significance value which was 0.00 . It means that there was a significant difference in speaking achievement between the students who were taught by using Six Thinking Hats and those who were not. Furthermore, all aspects showed the significant contributions in the speaking achievement.

\subsubsection{Interaction Effect of Six Thinking Hats Strategy and Critical Thinking}

The writer used two way ANOVA to find out the interaction effects of the STH and critical thinking on students' speaking achievement. Table 3 shows the summary of Two-way ANOVA.

Table 3. Summary of Two-way ANOVA

\begin{tabular}{|c|c|c|c|c|c|c|}
\hline Aspexts of Speeking & Szuice & $\begin{array}{l}\text { Type III Sum } \\
\text { of Sxuares }\end{array}$ & df & $\begin{array}{l}\text { Wean } \\
\text { Sqdare }\end{array}$ & $f$ & Sig \\
\hline Speak่าร̧ Total & CTgp Thiecia & 3.51 & 2 & 0.25 & 0.34 & 0.95 \\
\hline Comuratension & CTgFrlseos & $2.6 \hat{s}$ & 2 & Qji & 2.46 & C.99 \\
\hline Fluerky & CTpFoliecia & 2.25 & 2 & $\therefore 130$ & 3.00 & {$[.5]$} \\
\hline Vacabulary & CTgF"líeca & 3.54 & 2 & 0.4 & 1.14 & {$[.23$} \\
\hline Pronurkiation & CTgFinieca & 2.28 & 2 & $\therefore 14$ & 3.26 & C.0. \\
\hline Grammatr & CTgp" kieca & $1.2 \hat{j}$ & 2 & 0.63 & $1, \pi$ & C.13 \\
\hline
\end{tabular}

From the table above, it was shown that there were no significant interaction effect between the STH and critical thinking on speaking achievement since the significance value was higher than 0.05 . However, pronunciation was the only aspect which had some significant difference which showed that there was a partial interaction effect between the STH and critical thinking on speaking achievement. Furthermore, in analyzing the significant differences in speaking achievement among the levels of critical thinking (High, Mid, and Low), the writer used t-test. The results of the speaking achievement of both groups among the levels of critical thinking can be seen in Table 4.

Table 4. Summary of Students Speaking Achievement among the levels of CT

\begin{tabular}{cccccccc}
\hline \multirow{2}{*}{$\begin{array}{c}\text { Aspects of } \\
\text { Speaking }\end{array}$} & \multicolumn{2}{c}{$\begin{array}{c}\text { High- } \\
\text { Medium }\end{array}$} & \multicolumn{2}{c}{ High-Low } & \multicolumn{2}{c}{$\begin{array}{c}\text { Medium- } \\
\text { Low }\end{array}$} \\
\cline { 2 - 7 } & $\mathrm{t}$ & $\begin{array}{c}\text { Sig } \\
(2- \\
\text { tailed })\end{array}$ & $\mathrm{t}$ & $\begin{array}{c}\text { Sig } \\
(2- \\
\text { tailed })\end{array}$ & $\mathrm{t}$ & $\begin{array}{c}\text { Sig } \\
(2- \\
\text { tailed) }\end{array}$ \\
\hline $\begin{array}{c}\text { Speaking Total } \\
\text { Control Group }\end{array}$ & 0.41 & 0.68 & 0.45 & 0.65 & 0.86 & 0.40 \\
\hline Comprehension & 0.61 & 0.54 & 0.14 & 0.89 & 0.44 & 0.66 \\
\hline Fluency & 0.40 & 0.69 & 1.13 & 0.27 & 0.78 & 0.44 \\
\hline Vocabulary & 0.23 & 0.82 & 0.24 & 0.80 & 0.00 & 1.00 \\
\hline Pronunciation & 0.83 & 0.41 & 0.20 & 0.84 & 1.10 & 0.28 \\
\hline Grammar & 0.35 & 0.72 & 1.48 & 0.15 & 1.30 & 0.21 \\
\hline $\begin{array}{c}\text { Speaking Total } \\
\text { Exp. Group }\end{array}$ & 2.27 & 0.03 & 0.78 & 0.44 & 2.24 & 0.04 \\
\hline Comprehension & 2.35 & 0.03 & 0.20 & 0.84 & 3.00 & 0.009 \\
\hline Fluency & 0.64 & 0.09 & 0.55 & 0.58 & 3.13 & 0.007 \\
\hline Vocabulary & 1.72 & 0.10 & 1.68 & 0.11 & 0.23 & 0.81 \\
\hline Pronunciation & 2.66 & 0.01 & 1.59 & 0.13 & 1.21 & 0.24 \\
\hline Grammar & 1.70 & 0.11 & 1.09 & 0.29 & 1.03 & 0.31 \\
\hline
\end{tabular}

From the table above, the results in the control group showed that there were no significant differences in speaking achievement between high-medium, high-low and mediumlow levels of critical thinking. While the results in the experimental group showed that there was a significant difference between high and medium levels of students' critical thinking with the significance value of 0.03 . Meanwhile, the medium-low levels of critical thinking showed a significant difference with the significance value of 0.04 . However, it was found that the students in high-medium levels of critical thinking got significant differences in comprehension (0.03) and pronunciation (0.01) aspects. Meanwhile, the students in medium-low levels of critical thinking had significant differences in comprehension (0.009) and fluency (0.007) aspects.

\section{DISCUSSIONS}

From the results, it could be seen that the students in the experimental group performed well in all aspects with the highest scores in terms of vocabulary, fluency and comprehension aspects. It might be caused by the treatment which was using STH that required the students to learn the material they were going to present before they speak. Therefore, they tend to have a preparation to add the new words related to the material they were going to present in front of the class. According to Hanesova (2014, p. 44), the vocabulary was directly connected with the field of study or profession of the learners, or even (in some cases) with their personal perception and experiences that people need. Besides, the students tend to be more fluent in speaking because this strategy encouraged them to be more comfortable to speak to share their ideas and thoughts. However, the lowest improvement in the aspect of speaking was in the grammar. It might be caused by their lack of practice in enriching their grammar comprehension.

This study also investigated critical thinking as the moderator variable. Based on the result of the two-way ANOVA analysis, there was no significant interaction effect between the strategy and the critical thinking. However, this also might be caused by the writer who only gave the critical thinking test in order to see the students' level of critical thinking. Che (2002) states that critical thinking is a complex skill, it involves overcoming not only intellectual barrier but also psychological barriers. It might be caused by the people who are more comfortable with the established ideas and thinking habits. Meanwhile, it was also found that pronunciation was the only aspect that had the interaction with the strategy used and the students' critical thinking. Gilakjani (2011, p.79) states that learners need ample opportunity to listen to their own speech and that of fellow learners and to learn to distinguish the aspects of learners' pronunciation that make better comprehension. Therefore, it could be assumed that learners need to use their thinking in order to improve their better speaking with the good pronunciation.

Besides, the writer also analyzed the speaking achievement among the students who had low, medium and high levels of critical thinking in order to know their 
significant differences through t-test. The results of the experimental group showed that there were significant differences in the students who were in high-medium levels and medium-low levels of critical thinking especially in fluency, comprehension and pronunciation aspects.

\section{CONCLUSIONS}

Several conclusions could be drawn based on the research findings. Firstly, the Six Thinking Hats had successfully encouraged students to have better speaking achievement than those who were not taught by using this strategy. Secondly, there was a partial interaction effect between the strategy used and the critical thinking which was in pronunciation aspect. Thirdly, there were several aspects which had significant differences among the levels of students' critical thinking. Thus, it can be assumed that comprehension dominates the significant differences since each of thinking hats requires students to think deeply about something to solve the problem given. However, the good results of STH strategies are not limited to the speaking ability and they are helpful for other language skills. Thus the researchers of the study think that further research is needed to investigate the impact of using STH on the other language skills and sub-skills like listening comprehension, reading comprehension, writing, vocabulary and grammar. Furthermore, the effect of implicit and explicit teaching using the STH on EFL learners' different language skills and sub-skills also needs more research.

\section{REFERENCES}

Akhyak, A., Indramawan, A. (2013). Improving students' English speaking competence through storytelling. International Journal of Language and Literature, 1(2). Retrieved from http://www.ijllnet.com/journals/ijll/Vol_1_No_2_December_2013/3.pdf

Bono, E. D. (2004). Parallel thinking and the six hats. Retrieved from http://www.criticaleye.com/insightsservfile.cfm? $\mathrm{id}=238 \&$ view $=1$

Che, F. S. (2002). Teaching critical thinking skills in a Hong Kong secondary school. Asia Pacific Education Review, 3(1), 83-91. Retrieved from http://www.link.springer.com/article/10.007/fbf0302492 03.

Egege, S., Kutieleh, S. (2004). Critical thinking: Teaching foreign notions to foreign students. International Education Journal, 4(4). Retrieved from www. files.eric.ed.gov/fulltext/EJ903810.pdf

Febriyanti, E. R. (2011). Teaching speaking of English as a foreign language: Problems and solutions. Retrieved from http://www.download.portalgaruda.org/article.php?articl $\mathrm{e}=96563 \& \mathrm{val}=4806$

Gilakjani, A. P. (2011). Why is pronunciation so difficult to learn? English Language Teaching, 4(3), 74-83. Retrieved from http://files.eric.ed.gov/fulltext/EJ1080742.pdf

Hanesova, D. (2014). Development of critical thinking and creative thinking skills in CLIL. Journal of language and cultural education, 2(2), 33-51. Retrieved from http://c.users/owner/downloads/jolace2020142Hanesova.pdf

Masduqi, H. (2011). Critical thinking skills and meaning on English language teaching. TEFLIN Journal, 22(2), 185200. Retrieved from http://www.teflin.org/journal/index.php/journal/article/vi ewFile/26/27

Sanavi, R., Tarighat, S. (2014). Critical thinking and speaking proficiency: A mixed method. Theory and Practice in Language Studies, 4(1), 79-87. Retrieved from www.academypulication.com/issues/past/tpls/vol04/01/1 2.pdf 